materials are being studied in detail. New lead alloys, containing small quantities of cadmium and tin or antimony, developed by the Association for cable sheathing, are now finding increasing application in other fields. Tests are also being conducted with new materials for water pipes in which lead is alloyed with 0.05 to 0.06 per cent of tellurium. The effect of various soils on pipes of copper and these new alloys is also being investigated with the view of discovering the most suitable material for use in particularly corrosive soils.

A large amount of work of value in other directions is also recorded in the report. Methods have been devised by which small quantities of impurities in tin and lead can be determined spectroscopically in a few ininutes and with considerable exactness. Further work has also been done on copper and nickel and a start has been made with aluminium.

New materials for service at high temperatures are being developed by the addition of small quantities of various elements to copper-nickel alloys. The effects of the addition of aluminium and silicon to cupro-nickel containing 20 per cent or more nickel are being studied, and alloys have been found which give promise of useful commercial application. both with regard to maintenance of strength and resistance to steam corrosion at elevated temperatures.

An extensive service trial is being carried out by the London Midland and Scottish Railway Co. of new materials developed by the Association for firebox construction. In a locomotive the copper firebox is held in position by a number of rivetted copper stay rods, and it is estimated that, on the average, half the time a locomotive spends in the repair shops is due to failures in these stays. The trouble has now been traced to corrosion caused by boiler water leaking through the rivetted heads. By alloying the copper with small quantities of other substances and utilising a special heat treatment, the cause of the trouble is likely to be removed.

The utilisation of certain types of Empire copper for special purposes will be facilitated should investigations in progress on the removal of small quantities of bismuth from copper be successful.

The report records the practical completion of the researches which led to the production by the Association of aluminium brass condenser tubes. Their adoption practically solved the problem of the corrosion of condenser tubes in cases in which cupronickel tubes would be too costly. Other investigations in progress include those on the casting of aluminium and brass. The latter research has led to considerable improvements in the production of rolled brass sheet, of which tens of thousands of tons a year are produced in Great Britain.

\section{A Continuous Gas Indicator}

$\mathrm{T}$ HE technique of accurate gas analysis by chemical analysis is difficult, and expertness in the art can be acquired only by long apprenticeship. Moreover, the chemical method of analysis is not directly and readily adaptable to indicating and recording with accuracy the extent to which a constituent gas is present in a gaseous mixture. Such information is of very great importance in many industrial operations, and although chemical indicators and recorders, more especially for indicating and recording the presence of carbon dioxide and carbon monoxide, are available, their performance is, in general, not very satisfactory.

It is not surprising therefore that, in the last twenty years or so, physical principles have been employed in the design and construction of such instruments. These have included instruments dependent for their indications on density, calorific intensity, thermal conductivity, and in the case of an indicator recently devised by I. Fagelston, a combination of viscosity and velocity of effusion.

The principle of this last instrument is simple. The gaseous mixture and a standard gas flow through two similar capillary tubes, the outlet ends of which are enlarged and closed by two platinum plates pierced with similar orifices. The gases are sucked through the respective capillary tubes and orifices by a pump, and any difference of pressure at the exit ends of the capillary tubes, arising from difference in composition of the gases flowing in the tubes, is indicated by the difference of level of liquid in the limbs of a U-tube manometer connected with the respective ends.

Two forms of instrument incorporating this principle have been put on the market by Messrs. Griffin and Tatlock, Ltd. The first form, known as the "Air Type", uses air as the standard comparison gas; in the second form, known as the "Petrol Type", the comparison gas is made from the gas being analysed, by removing the constituent being determined. Generally an accuracy of indication of the order 0.05 per cent is possible with the instruments; very small vapour concentrations can be indicated to within 0.005 per cent. The instruments have numerous technical and scientific applications, including, for example, the indication of organic solvents, petrol vapour in air, the evaluation of adsorbents, in coal carbonisation for indicating carbon dioxide and hydrogen sulphide, and for the analysis of industrial gases, including the rare gases, for determining safety in connexion with chemical and engineering plant, and for indicating the humidity of gases.

\section{University and Educational Intelligence}

RESEARCH work in Slavonic countries is listed in catalogues which are being compiled and issued by the Russian Department of the University of Birmingham. Pamphlets relating to work $(a)$ in progress and (b) already published in Czechoslovakia and Poland in 1931-32 have already been issued and these will be followed by catalogues of work in three other Slavonic countries. The lists are arranged according to universities and faculties.

SUPERvised correspondence study of a new type has been introduced in the State of Nebraska with the object of widening at a minimum of expense the range of the curricula of the smaller high schools. The system is described in an article contributed by Prof. Platt of the University of Nebraska to the June number of School Life. The school time-table provides periods for the work and the scripts are regularly dispatched to the correspondence centre for examination and criticism. The supervising teacher does not need to be a specialist in all the subjects of the correspondence courses. It is his business to see that the pupils have the proper materials, attitude and environment, to interpret the questions, guide the pupils in the use of encyclo- 